\title{
A DIMENSÃO URBANÍSTICA DE GRANDES PROJETOS URBANOS: análise da Operação Urbana Consorciada Linha Verde, Curitiba, Brasil
}

\author{
Letícia Nerone Gadens \\ Professora e pesquisadora da Universidade Federal do Paraná (UFPR) \\ E-mail: leticia_gadens@yahoo.com.br
}

\section{RESUMO}

A pesquisa apoia-se na discussão de grandes projetos urbanos (GPUs) e de operações urbanas consorciadas (OUCs), instrumento frequentemente utilizado para viabilização de GPUs no cenário brasileiro. Esta pesquisa tem por objetivo verificar as consequências morfológicas da implementação do GPU Linha Verde, que consiste na reconversão funcional da antiga rodovia BR 166 em nova via urbana. Esta abordagem justifica-se tendo em vista que há poucas avaliações dos resultados obtidos a partir da dimensão urbanística de GPUs. Os procedimentos metodológicos consistem em pesquisa bibliográfica e interpretação documental, de modo a verificar determinados elementos constituintes da forma urbana, associados a padrões de maior sustentabilidade socioambiental e, portanto, maior eficácia na gestão do solo. Os resultados evidenciam um processo de transformação ainda incipiente e denotam a necessidade de aprofundamento na compreensão da dimensão morfológica do projeto. Além disso, indicam que a utilização do GPU, como catalizador para alterar as realidades preexistentes, ainda permanece débil.

Palavras-chave: Grandes projetos urbanos; Operação urbana consorciada; Gestão do solo urbano.

\begin{abstract}
The research is based on the discussion of large urban projects (GPUs) and consortiated urban operations (OUCs), an urban tool often used to make GPUs feasible in the Brazilian scenario. This research aims to verify the morphological consequences of the GPU Linha Verde implementation, which consists in the functional reconversion of the old BR 166 highway into a new urban road. This approach is justified considering that there are few evaluations of the results obtained from the urbanistic dimension of GPUs. The methodological procedures consist of bibliographical research and documentary interpretation, in order to verify certain constituent elements of the urban form, associated to higher social and environmental sustainability standards and, therefore, greater effectiveness in urban land management. The results show a process of transformation still incipient and denote the need to deepen the understanding of the morphological dimension of the project. In addition, they indicate that the use of the GPU, as a catalyst to change the preexisting realities, still remains weak.
\end{abstract}

Keywords: Large urban projects; Consortiated urban operation; Urban land management. 


\section{O CONCEITO DE GPU E A SUA DIMENSÃO URBANÍSTICA}

Este artigo faz parte de uma pesquisa mais abrangente ${ }^{1}$ e apoia-se na discussão de Grandes Projetos Urbanos (GPUs), caracterizados pela articulação entre plano e projeto, que visam promover transformações estruturais nas cidades. Embora possuam conceito difuso, em razão da diversidade de elementos que os caracterizam, os GPUs podem ser entendidos como instrumentos de política pública que geram impactos para além dos seus limites imediatos (Ultramari; Rezende, 2007). Também são interpretados como iniciativas de renovação urbana, orientadas por um plano que se apoia no redesenho do espaço (Someck; Campos Neto, 2005).

Em outra perspectiva, os GPUs são compreendidos por seu caráter de dominação territorial, tendo em vista que sua formulação se sustenta pela distribuição desigual do poder (Moulaert; Rodriguez; Swyngedouw, 2003). Harvey (2000) argumenta que na viabilização de GPUs o setor privado assume os lucros, enquanto que o poder público, os riscos resultantes de tais intervenções. Complementarmente, Lungo (2005) destaca uma questão de interesse para essa pesquisa, argumentando que os GPUs não se caracterizam apenas por constituírem-se grandes obras emblemáticas, mas também por definirem grandes operações urbanas viabilizadas por meio de um conjunto de ações de nível intermediário, cuja integração promove significativo impacto no desenvolvimento de uma cidade.

Desta forma, ressalta-se que a multiplicidade na definição de GPUs resulta em uma importante dificuldade na análise desse tema. Assim, os GPUs caracterizam-se por projetos de distintas tipologias, conteúdos programáticos, escalas e articulações de agentes envolvidos em sua implementação. No entanto, embora possam adquirir diferentes formatos, algumas questões são inerentes à estruturação de projetos dessa natureza, tais como a fundamentação em marco regulatório, incluindo planos e/ou instrumentos urbanísticos necessários à sua execução; a articulação e papel desempenhado pelos agentes envolvidos no processo; a forma de financiamento para viabilidade de sua implementação; a localização e consequente gestão do solo urbano em que se dará tal intervenção. Assim, são projetos que trazem consigo certa complexidade.

Além disso, os GPUs inserem-se no contexto de transição entre o planejamento regulatório e o estratégico (Portas, 2003). Especificamente no cenário brasileiro, sua implementação está alinhada a distintos modelos de gestão urbana, adotados a partir da década de 1970, ora com maior poder centralizador do Estado, ora com abertura para a participação mais democrática da sociedade (Gadens; Hardt; Frey, 2011). Especialmente a partir da década de 1990, a gestão brasileira tem orientado o planejamento urbano a práticas alinhadas ao crescimento econômico e a promoção da competitividade, inerentes à concepção do planejamento estratégico.

Nesse sentido, Vainer, Oliveira, Lima Junior (2012, p. 14) argumentam que a reflexão crítica a esse modelo sustentado pelo planejamento estratégico que envolve "[...] conceitos, retóricas e representações do que é e do que deve ser a cidade [...] tem que focalizar centralmente a performance dos grandes projetos urbanos". Dessa forma, a pesquisa mais abrangente, da qual este trabalho faz parte, visa contribuir com a discussão sobre a atual justaposição entre plano e projeto urbano, explicitada pela natureza dos GPUs, tendo em vista a configuração de um novo modelo de planejamento, oposto ao tradicional, caracterizado pela dispensa da precedência entre plano e projeto; flexibilidade normativa; distinta articulação de agentes envolvidos e não linearidade no processo.

Nesse artigo, essa questão será abordada de forma parcial, por meio da avaliação e discussão dos resultados morfológicos decorrentes da implantação do GPU Linha Verde, situado em Curitiba, Brasil. Nesse sentido, essa investigação tem por objetivo central verificar as consequências morfológicas da implementação desse GPU, viabilizado por meio de uma Operação Urbana Consorciada (OUC). Portanto, o estudo estrutura-se a partir da observação empírica de um caso concreto, cuja verificação visa contribuir para a construção, no conjunto da pesquisa, de um referencial teórico brasileiro sobre o tema.

Esta abordagem justifica-se tendo em vista que há poucas avaliações que se debrucem sobre a dimensão urbanística dos GPUs, ou seja, estudos voltados à análise dos resultados morfológicos derivados do projeto implantado. Dessa forma, algumas questões estruturam a presente pesquisa, tais como:

\footnotetext{
${ }^{1}$ Este artigo integra os resultados parciais da pesquisa intitulada "Plano e projeto na cidade contemporânea: estudo a partir da relação entre uso e ocupação do solo e transporte coletivo à luz da experiência de Curitiba" (ID PROJETO: 23651, BANPESQ: 2016023651), coordenada pela autora e desenvolvida no âmbito das atividades do Grupo de Pesquisa Cidade, Meio Ambiente e Políticas Públicas (CIMAPP) e do Laboratório de Habitação Urbanismo (LAHURB), do Departamento de Arquitetura e Urbanismo, Setor de Tecnologia, da Universidade Federal do Paraná (UFPR).
} 
a) Quais resultados morfológicos têm sido gerados a partir da implementação de GPUs?

b) Em que medida tais resultados tem contribuído para alterar as realidades preexistentes, tendo em vista que a sua implementação se justifica em razão da necessidade de transformação territorial e redesenho de espaços, que estejam adequados às novas dinâmicas e demandas urbanas?

Além disso, essa pesquisa pretende aprofundar a discussão de GPUS no cenário latino-americano e, em específico, brasileiro, considerando que não se deve subestimar seu potencial enquanto agente catalizador de mudanças que contribuam com a redução de desigualdades socioespaciais presentes nessas realidades. As experiências precedentes de GPUs e, o decorrente posicionamento crítico a respeito do tema reforçam o seu papel como promotor de maior segregação socioespacial nas cidades, contribuindo com processos de gentrificação e com o deslocamento da população residente, favorecendo, portanto, a apropriação individual da valorização da terra urbana (Lungo, 2005).

Considerando esse contexto, Vainer, Oliveira, Lima Junior (2012) propõem uma avaliação de como os impactos dos GPUs tem contribuído, ou não, para a redução da desigualdade e fortalecimento democrático nas cidades brasileiras. Assim, os autores apresentam uma matriz analítica que engloba distintas dimensões de análise, ${ }^{2}$ entre as quais a arquitetônico-urbanística, a qual seria caracterizada pela avaliação dos atores responsáveis pela elaboração e implantação do projeto; das referências urbanísticas; do programa e do partido arquitetônico/urbanístico do projeto e sua relação com o entorno e com a cidade; da linguagem arquitetônica adotada e do padrão tecnológico da obra; das obras de infraestrutura planejadas e executadas em função do projeto; dos instrumentos urbanísticos e/ou fundiários relacionados ao uso e ocupação do solo.

Segundo Férran (2001), os GPUS devem ser avaliados considerando que seus efeitos territoriais apesentam um caráter multifacetário sobre diversos aspectos: sobre o sistema urbano (provocando integração ou separação espacial); sobre as condições econômico-culturais (distribuindo ou concentrando riqueza); sobre o nível de competitividade da cidade; sobre a forma de governo (descentralizado ou centralizado); sobre o planejamento urbano (fortalecendo ou debilitando); entre outros.

Considerando o referencial teórico e as questões que estruturam essa pesquisa, esse trabalho volta-se a avaliação da dimensão urbanística, por meio dos resultados morfológicos decorrentes da implantação de um GPU. A morfologia urbana trata do estudo do meio físico da forma, dos processos e das pessoas que o formataram (Rossi,2001; Lamas, 2007; Oliveira, 2018). Portanto, nesta pesquisa considera-se o estudo da forma do objeto empírico, não apenas como resultado físico, mas também a partir da observação de elementos alinhados a padrões que assegurem maior sustentabilidade, na medida em que podem contribuir para maior eficiência na gestão do solo urbano (Jabareen,2006; Dempsey, et. al 2010).

\section{A OUC COMO INSTRUMENTO ASSOCIADOS À VIABILIZAÇÃO DE GPUS}

No cenário brasileiro, alguns instrumentos têm sido associados à viabilização de GPUs, como as Operações Urbanas Consorciadas (OUCs), que consistem em intervenções coordenadas pelo poder público municipal, com a participação de diversos atores, para viabilizar transformações urbanísticas estruturais (Brasil, 2001). A própria concepção legal do instrumento, ao mencionar "transformações urbanísticas estruturais" alinha-se ao conceito anteriormente discutido de grande projeto urbano.

O Estatuto da Cidade (Brasil, 2001) define que as OUCs podem prever, entre outras medidas, a alteração de parâmetros urbanísticos, tais como, índices e características de parcelamento, uso e ocupação do solo; regularização de construções executadas em desacordo com a norma vigente; e incentivos a operações que utilizem tecnologias para redução de impactos ambientais. A lei ainda prevê a necessidade de elaboração de um plano prévio que contenha a definição da área a ser atingida; o programa básico de ocupação; o programa de atendimento econômico e social para a população afetada; as finalidades da operação; o estudo prévio de impacto de vizinhança; a natureza dos incentivos a serem concedidos e contrapartidas a serem exigidas dos proprietários, usuários permanentes e investidores; e a forma de controle da operação compartilhado com a sociedade civil. Além disso, estabelece a possibilidade de emissão de certificados de potencial adicional de construção (CEPACs), alienados em leilão ou utilizados diretamente no pagamento das obras necessárias à operação.

\footnotetext{
2 A matriz analítica proposta pelos autores aborda os projetos urbanos a partir da análise das dimensões política, institucional, simbólica, arquitetônico-urbanística, fundiária, socioambiental e econômico-financeira (Vainer; Oliveira; Lima Junior, 2012).
} 
A experiência geral de implantação desse instrumento vem demonstrando a importância da relação entre o poder público e o setor privado na transformação do espaço urbano. No entanto, a despeito dos aspectos positivos, os resultados têm, de modo geral, evidenciado práticas de desconexão do tecido urbano, envolvido na operação, com suas áreas lindeiras, além da excessiva participação do mercado na tomada de decisões, estabelecendo operações imobiliárias altamente lucrativas que geram, por consequência, espaços gentrificados e de segregação espacial e social.

Assim, experiências envolvendo a utilização desse instrumento trazem consigo questões que colocam em dúvida os preceitos originais de sua proposição (Fix, 2001). Segundo a autora, a análise conceitual da OUC não evidencia os resultados práticos de sua aplicação. Diante da realidade brasileira, o instrumento tem acentuado a desigualdade e a exclusão socioespacial, favorecendo a acumulação de capital por setores específicos da sociedade e de forma institucionalizada pelo próprio Estado.

Por outro lado, Alfonsin (2006) defende que a aplicação das OUCs pode corrigir processos excludentes evidenciados nas cidades brasileiras, possibilitando a distribuição dos ônus e benefícios dos processos de urbanização. A autora enfatiza que a aplicação do instrumento permite a inversão da lógica de investimentos em áreas valorizadas e de interesse do mercado a partir do momento em que "o poder público identifica oportunidades de financiamento de obras de interesse público por setores da iniciativa privada beneficiados com a flexibilização do regime urbanístico no marco de uma operação urbana" (Alfonsin, 2006, p. 294).

Nesse sentido, o reconhecimento da OUC, como um instrumento de intervenção urbana e de viabilização de GPUs, traz consigo o desafio de equacionar a dimensão econômica, necessária para sua viabilização, e a dimensão urbanística do projeto, de forma que seu desenho possa contribuir com a reversão do quadro de desigualdades socioespaciais vigente nas cidades brasileiras.

\section{CASO CONCRETO DE ANÁLISE - GPU LINHA VERDE}

O caso concreto de análise desse estudo corresponde ao GPU Linha Verde, situado em Curitiba, Brasil. Esse projeto consiste na reconversão funcional da antiga rodovia BR $166 \mathrm{em}$ um importante eixo de conexão na escala urbana e metropolitana. A consolidação desse processo pode permitir a integração de 22 bairros (30\% do total da cidade), segundo a concepção proposta no desenho da operação (IPPUC, FIPE, 2012).

O projeto está sendo viabilizado por meio da aplicação do instrumento OUC, proposta em 2011, a qual tem por objetivo captar recursos para a complementação das obras de sistema viário e transporte, oferta de espaços de uso público e promoção da requalificação urbanística (Curitiba, 2011). Aprovada pela Lei Municipal n.․ Lei 13.909/2011, a OUC engloba áreas adjacentes e contínuas à antiga rodovia, configurando três setores: norte, centro e sul, em um perímetro de $20.820 .506 \mathrm{~m}^{2}$, com população de 82.000 habitantes, o que corresponde a 4,68\% do total do município de Curitiba (IPPUC, FIPE, 2012). 


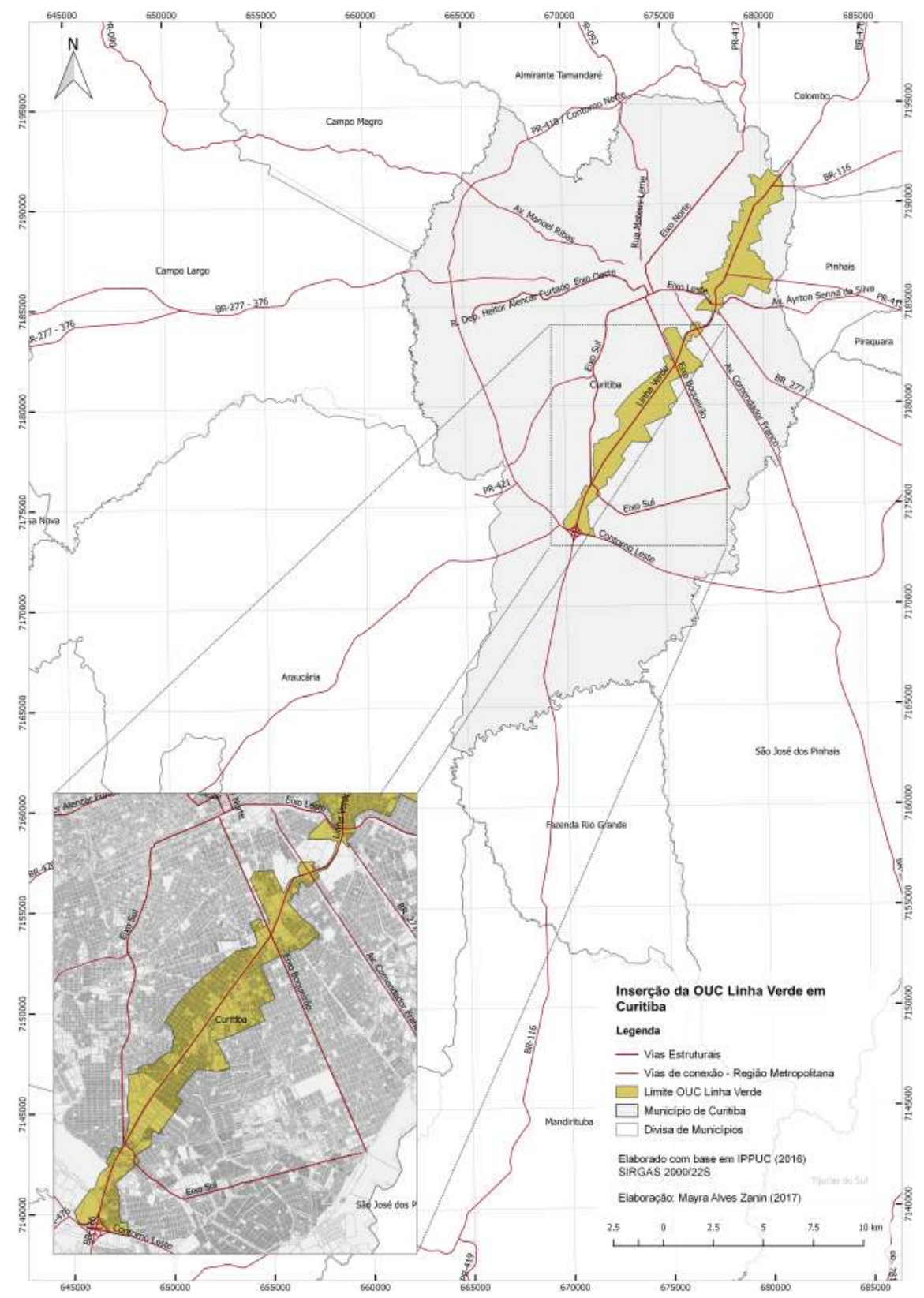

Inserção da OUC Linha Verde na cidade de Curitiba, com destaque para o setor sul, objeto de análise nesta pesquisa Fonte: Elaborado com base em Curitiba (2011)

Curitiba é polo de uma região metropolitana formada por 29 municípios, com população de 1.751 .907 habitantes (IBGE, 2010), que corresponde a $54,34 \%$ da população metropolitana, equivalente à 3.223.836. A antiga rodovia BR 116, que estabelecia a conexão entre São Paulo e a região sul do Brasil, possuía extensão de aproximadamente $30 \mathrm{~km}$, no município de Curitiba, secionando-o no sentido leste-oeste. $\mathrm{Na}$ época de sua construção, durante a década de 1950, o seu traçado estava a leste da cidade e distante da porção urbanizada. No entanto, com o passar do tempo, o crescimento populacional e, consequente consolidação da ocupação urbana nessa área, fez com que a rodovia BR 116 passasse a se configurar como uma barreira, ou seja, um elemento divisor da cidade (IPPUC; FIPE, 2012).

Diversos projetos e ações foram realizados no intuito de promover melhorias nessa região, inicialmente visando à integração dos dois lados da rodovia, até o surgimento do projeto Linha Verde, em 2000, que resultou, posteriormente, na proposição da OUC Linha Verde, com o objetivo de transformar a ocupação do entorno da antiga rodovia (IPPUC, FIPE, 2012). Nesse sentido, a implantação do projeto Linha Verde antecede à OUC de mesmo nome. Sua execução foi dividia em quatro trechos: 


\begin{tabular}{|c|c|c|c|c|}
\hline & TRECHO & $\begin{array}{c}\text { ANO DE } \\
\text { CONCLUSÃO DA } \\
\text { OBRA }\end{array}$ & FINANCIAMENTO & $\begin{array}{l}\text { INSTRUMENTOS } \\
\text { URBANÍSTICOS } \\
\text { INCIDENTES AO LONGO } \\
\text { DO TEMPO }\end{array}$ \\
\hline 1 & Linha Verde Sul & 2009 & $\begin{array}{l}\text { BID (Banco Interamericano de } \\
\text { Desenvolvimento) }\end{array}$ & \multirow{4}{*}{$\begin{array}{l}\text { Zoneamento } \\
\text { OODC e } \\
\text { OUC }\end{array}$} \\
\hline 2 & Linha Verde Norte & Em execução & $\begin{array}{l}\text { Agência Francesa de } \\
\text { Desenvolvimento (AFD) - parcial }\end{array}$ & \\
\hline 3 & \multirow{2}{*}{$\begin{array}{l}\text { Linha Verde Sul } \\
\text { (Pinheirinho - } \\
\text { Contorno Sul) }\end{array}$} & \multirow[t]{2}{*}{-} & PAC Mobilidade & \\
\hline 4 & & & - & \\
\hline
\end{tabular}

Resumo da execução do projeto Linha Verde, período 2000 a 2016

Fonte: Elaborado com base em IPPUC; FIPE (2012)

Desde o ano 2000, foram propostos mecanismos de estímulo e incentivo à ocupação urbana nesta área, definindo inicialmente a Linha Verde como Eixo de Adensamento, na Lei Municipal n. 0 9.800/2000 e, posteriormente, no Plano Diretor de 2004, como Eixo Estruturante, caracterizado pela integração do uso e ocupação do solo, sistema vário e transporte coletivo, com a presença do BRT, princípios estes que guiaram o desenvolvimento de Curitiba a partir do Plano Preliminar de Urbanismo, proposto em 1965. Portanto, visando sua reconversão em via urbana, foram usados, ao longo do tempo, distintos instrumentos urbanísticos como o zoneamento, a outorga onerosa do direito de construir (OODC) e, por fim, a proposição da OUC.

O projeto previsto na OUC Linha Verde prevê algumas intervenções fundamentalmente relacionadas à infraestrutura de mobilidade urbana (ligações viárias em desnível, ampliação e melhoria do sistema de transporte coletivo urbano e metropolitano); oferta de espaços coletivos (parques, espaços de convivência, equipamentos urbanos e comunitários) e; moradia, com a previsão de programas de habitação de interesse social em áreas de risco (IPPUC, FIPE, 2012).

O Estudo de Impacto de Vizinhança (EIV) elaborado para a operação definia o instrumento como exceção a lei de zoneamento, uso e ocupação do solo, utilizado como "[...] estratégia para requalificar compartimentos urbanos das cidades, bem como para implantar e ampliar sua infraestrutura, por meio de intervenções em áreas onde haja interesse imobiliário com demanda acima dos limites estabelecidos pela legislação urbanística" (IPPUC, FIPE, 2012, p. 70).

Nesse sentido, os parâmetros urbanísticos foram definidos de modo a prever diferentes zonas de uso, cujos parâmetros construtivos são descritos na tabela abaixo.

\begin{tabular}{|c|c|c|c|c|}
\hline \multirow[t]{3}{*}{ ZONA } & \multicolumn{4}{|c|}{ PARÄMETROS CONSTRUTIVOS } \\
\hline & \multicolumn{2}{|c|}{ BÁSICO } & \multicolumn{2}{|c|}{ POTENCIAL ADICIONAL } \\
\hline & COEFICIENTE & ALTURA & COEFICIENTE & ALTURA \\
\hline PÓLO-LV & 1,0 & Livre & 4,0 & Livre \\
\hline SE-LV & 1,0 & 6 & 4,0 & Livre \\
\hline ZT-LV & 1,0 & 4 & 2,5 & 8 \\
\hline ZE-D & 0,5 & 4 & $\begin{array}{c}2,5 \text { (Hab. trans.) } \\
1,0 \text { (Com.) }\end{array}$ & 8 \\
\hline ZR4 & 2,0 & 6 & 2,5 & 8 \\
\hline
\end{tabular}

Resumo dos parâmetros urbanísticos previstos na OUC Linha Verde

Fonte: Elaborado com base em Curitiba (2011)

Este estudo está centrado na análise do setor sul da OUC Linha Verde, considerando que esta é a área de maior consolidação do processo de transformação e que, pode permitir, portanto, melhores condições de avaliação dos resultados morfológicos decorrentes da implementação da operação. A seguir, são delineados os procedimentos metodológicos que conduziram tal avaliação, visando o atendimento do objetivo central desta pesquisa, que consiste em verificar as consequências morfológicas da implementação desse GPU.

\section{CONSIDERAÇÕES METODOLOGICAS}

O desenvolvimento desta pesquisa fundamenta-se na análise de um estudo de caso, utilizando-se de métodos exploratórios, descritivos e analíticos. Este estudo é de natureza aplicada, tendo em vista que se volta à utilização do conhecimento em situação prática (Silva; Menezes, 2005), visando responder as 
questões estruturantes da pesquisa, tais como quais resultados morfológicos têm sido gerados a partir da implementação de GPUs e em que medida estes tem contribuído para alterar as realidades preexistentes.

Assim, os procedimentos e técnicas que subsidiaram o estudo em questão constituem-se, primordialmente de: pesquisa bibliográfica, interpretação documental e verificação em campo. O recorte espacial de análise compreende o setor sul da OUC Linha Verde. Este setor, como mencionado anteriormente, além de ser o mais consolidado no processo de transformação, também permitiu a verificação dos resultados da OUC após a conclusão das obras previstas no projeto, em 2009. Tendo em vista que o objetivo desta pesquisa se fundamenta na avaliação do instrumento OUC, o recorte temporal adotado compreende o período de 2011, ano de aprovação da OUC Linha Verde, até 2016, período mais recente de disponibilização dos dados necessários à pesquisa.

A definição dos indicadores de avaliação morfológica do GPU fundamentou-se em referência bibliográfica que os reconhece como elementos constituintes da forma urbana, sendo conceitos frequentemente associados a padrões urbanos de maior sustentabilidade socioambiental (Jabareen, 2006; Dempsey, et. al, 2010). Nesse sentido, os indicadores de análise correspondem à avaliação da compacidade, densidade e diversidade do setor sul da Linha Verde.

A compacidade consiste em uma métrica espacial que relaciona a forma urbana e sua desagregação. Assim, está relacionada a três características fundamentais: maiores densidades, diversidade de funções e diversidade social (Dantzig, Saaty,1973; Jacobs, 2000). Cidades ou espaços urbanos mais compactos tendem a potencializar as relações de vizinhança entre residentes e visitantes, aumentando a probabilidade de contato e de comunicação entre diversos agentes e elementos do sistema urbano (Rueda, 2012.; Jacobs, 2000).

Além do critério de compacidade, foram avaliados a densidade, que segundo Acioly e Davidson (1998) consiste em um dos mais relevantes parâmetros de desenho urbano, utilizados no processo de planejamento. É importante considerar que esse parâmetro tem uma dimensão cultural, sendo, portanto, um indicador relativo, vinculado a determinado contexto (Dempsey; et. al, 2010).

O último critério de avaliação corresponde à diversidade, a qual pode assumir distintas dimensões, relacionando-se a aspectos funcionais como a variedade de usos do solo; físicos, como a tipologias de edificações; mas também a questões econômicas e sociais. Rueda (2012) argumenta que esse indicador permite a identificação da complexidade urbana, ou seja, do grau de informações dispostas sobre um território, que estabeleçam relações múltiplas e variadas entre si. Nesta pesquisa, considerou-se inicialmente a avaliação da combinação de usos residenciais, comerciais e de serviços, portanto, a variedade de usos do solo.

Os três indicadores de avaliação são complementares entre si, tendo em vista que as dimensões da diversidade associadas à densidade são fundamentais para a leitura da compacidade urbana, na medida em que também está associada a maiores densidades e a presença de diversidade funcional e social.

\begin{tabular}{|lll|}
\hline \multicolumn{1}{|c}{ INDICADORES } & \multicolumn{1}{c}{ VARIÁVEIS } & \multicolumn{1}{c}{ DESCRIÇÃO } \\
\hline Compacidade & Índice de relação compacta & $\begin{array}{l}\text { Relação da área com o perímetro do compartimento de } \\
\text { análise. }\end{array}$ \\
\cline { 2 - 3 } & Cheios e vazios & $\begin{array}{l}\text { Proporção de áreas "vazias" em relação à área líquida total } \\
\text { da OUC LV - setor sul. }\end{array}$ \\
\hline Densidade & Densidade líquida & $\begin{array}{l}\text { Proporção de lotes residenciais em relação ao número total } \\
\text { de lotes OUC LV - setor sul. }\end{array}$ \\
\hline Diversidade & Equilíbrio entre atividade e residência & $\begin{array}{l}\text { Cálculo do total de superfície para o uso terciário em relação } \\
\text { ao total da superfície lucrativa. }\end{array}$ \\
\hline
\end{tabular}

Síntese dos indicadores considerados para a análise da OUC Linha Verde - setor sul

Fonte: Elaborado com base em Acioly, Davidson (1998); Jabareen (2006); Dempsey et. al (2010); Rueda (2012)

Nesse sentido, os dados coletados e analisados integram os indicadores da pesquisa. Os dados secundários são provenientes de documentos e informações oficiais publicados pela Prefeitura Municipal de Curitiba, os quais possibilitaram a avaliação geral do setor de análise. Além disso, dados primários foram verificados em campo, a fim de complementar os resultados indicados pelos dados secundários. 
Cada indicador foi avaliado considerando determinadas variáveis que o compõe. Ressalta-se que constitui parte do desenvolvimento futuro dessa pesquisa a inserção de outras variáveis que podem ser incorporadas a analises desses indicadores, de forma a complementar e aprofundar a avaliação do estudo.

\section{ANÁLISE DOS RESULTADOS}

Com o objetivo de responder à questão central da pesquisa, que consiste em avaliar e discutir os resultados morfológicos decorrentes da implantação do GPU Linha Verde, situado em Curitiba, foram aplicados os indicadores de análise anteriormente citados.

O indicador de compacidade foi avaliado por meio do índice de relação compacta, que corresponde ao fator de desagregação dos espaços urbanos. Segundo Lu e Liu (2015, p. 2609), "uma cidade compacta, em oposição a uma cidade extensa, sugere alta eficiência na organização das atividades urbanas em uma área relativamente pequena". Os resultados obtidos pela avaliação comparativa da compacidade na cidade de Curitiba, na extensão total da OUC Linha Verde e no setor sul da operação estão demonstrados no gráfico abaixo.

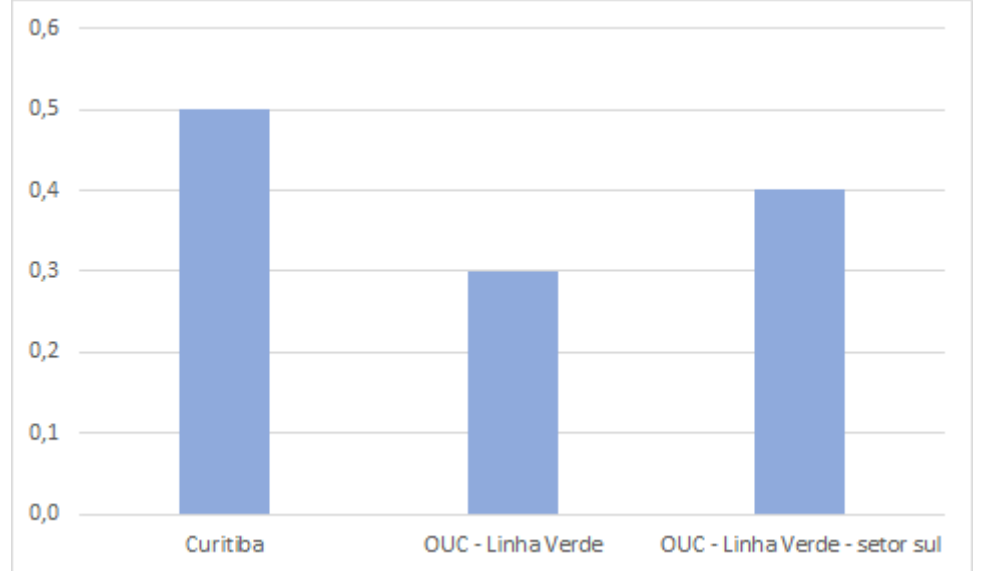

\begin{tabular}{ll}
\multicolumn{2}{c}{ Padrão de referência } \\
$>0,5$ & Compacto \\
$0,2-0,5$ & Menos \\
$0,15-0,2$ & compacto \\
& Disperso \\
$<0,15$ & Muito \\
disperso
\end{tabular}

Resultados obtidos a partir da análise do incide de relação compacta na cidade de Curitiba, OUC Linha Verde e OUC Linha Verde - setor sul

Fonte: Elaborado pela autora com base em Richardson (1973 apud Lu, Liu; 2015) e Curitiba (2011)

Os resultados obtidos evidenciam que a cidade de Curitiba se encontra nos limites da referência estabelecida para uma cidade dita compacta $(0,5)$. O setor sul da OUC LV apresenta índice de compacidade igual a 0,4, o qual, embora pouco inferior ao dado geral auferido para Curitiba, manteve-se ao longo dos anos de análise, relacionando-se também a um padrão de menor compacidade urbana. Esse dado pode ser consequência de um processo de transformação urbana ainda em curso, ao considerar que as preexistências do local (usos, infraestruturas, estrutura fundiária, entre outros) são aspectos de relevância que influenciam o processo em razão do seu grau de consolidação e; do fato de que os parâmetros definidos na OUC Linha Verde, os quais estabelecem maiores densidades construtivas e habitacionais, em relação as anteriormente previstas, ainda não foram totalmente aplicados.

Por outro lado, o índice de relação compacta obtido para a OUC Linha Verde - setor sul pode ser indício de que a própria concepção da OUC pode corresponder a um modelo de cidade caracterizado pela necessidade de maior consumo de solo. No entanto, ressalta-se que outros critérios de análise, tais como densidade construtiva e habitacional, bem como diversidade de atividades econômicas e padrões de deslocamentos, deverão ser incorporados futuramente a presente pesquisa para maior aprofundamento e verificação dessa hipótese.

Complementarmente, para a avaliação do indicador de compacidade, procedeu-se a averiguação da proporção entre lotes vazios e ocupados, classificados na base cadastral do município como territoriais e prediais, respectivamente. Essa avaliação teve por objetivo verificar qual o potencial de transformação desse espaço urbano, em consonância com o projeto proposto, a partir da ocupação de áreas vazias ou da alteração de usos em áreas já ocupadas.

Os resultados iniciais, obtidos nesta pesquisa, indicam ligeira redução na proporção entre lotes ocupados e desocupados, com o acréscimo de quase $3 \%$ de lotes considerados com construção, no período de seis 
anos de análise. Dessa forma, as áreas que ainda se encontram vazias estão sendo progressivamente ocupadas com novas edificações. Ao se verificar a espacialização desses dados, observa-se que as áreas vazias correspondem a terrenos de aproximadamente $1.800 \mathrm{~m}^{2}$ e concentram-se na porção extremo sul da área de análise, portanto, mais afastadas de áreas mais centrais e previamente consolidadas. Constata-se ainda o predomínio de lotes classificados como prediais correspondentes a $89 \%$ do total do número de lotes, no último ano de análise, o que ilustra o grau de consolidação da área.

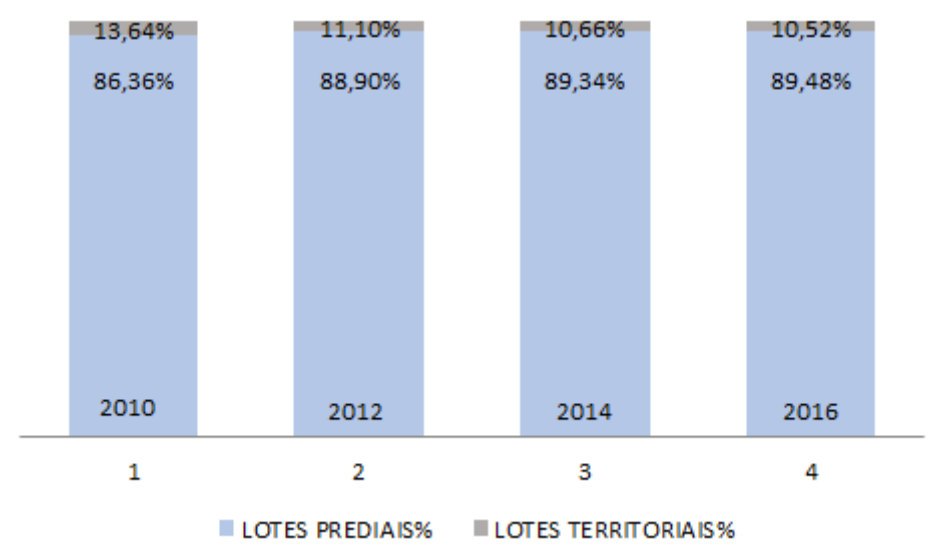

Proporção de lotes vazios e ocupados, no setor sul da Linha Verde, no período de 2010 a 2016 Fonte: Elaborado pela autora com base em IPPUC $(2010,2012,2014,2016)$

No entanto, a despeito da consolidação da ocupação no espaço de análise, verifica-se uma tendência expressiva na alteração de usos, sobretudo em relação à presença de usos residenciais, os quais, anteriormente ao início da OUC, eram equivalentes a $45 \%$ do número total de lotes. Nesse sentido, verificase que, entre os anos 2011 e 2016 houve um processo de reversão desse quadro, com aumento expressivo da presença de lotes com usos residenciais, equivalentes a $70 \%$ do número total de lotes, no último ano de análise. 


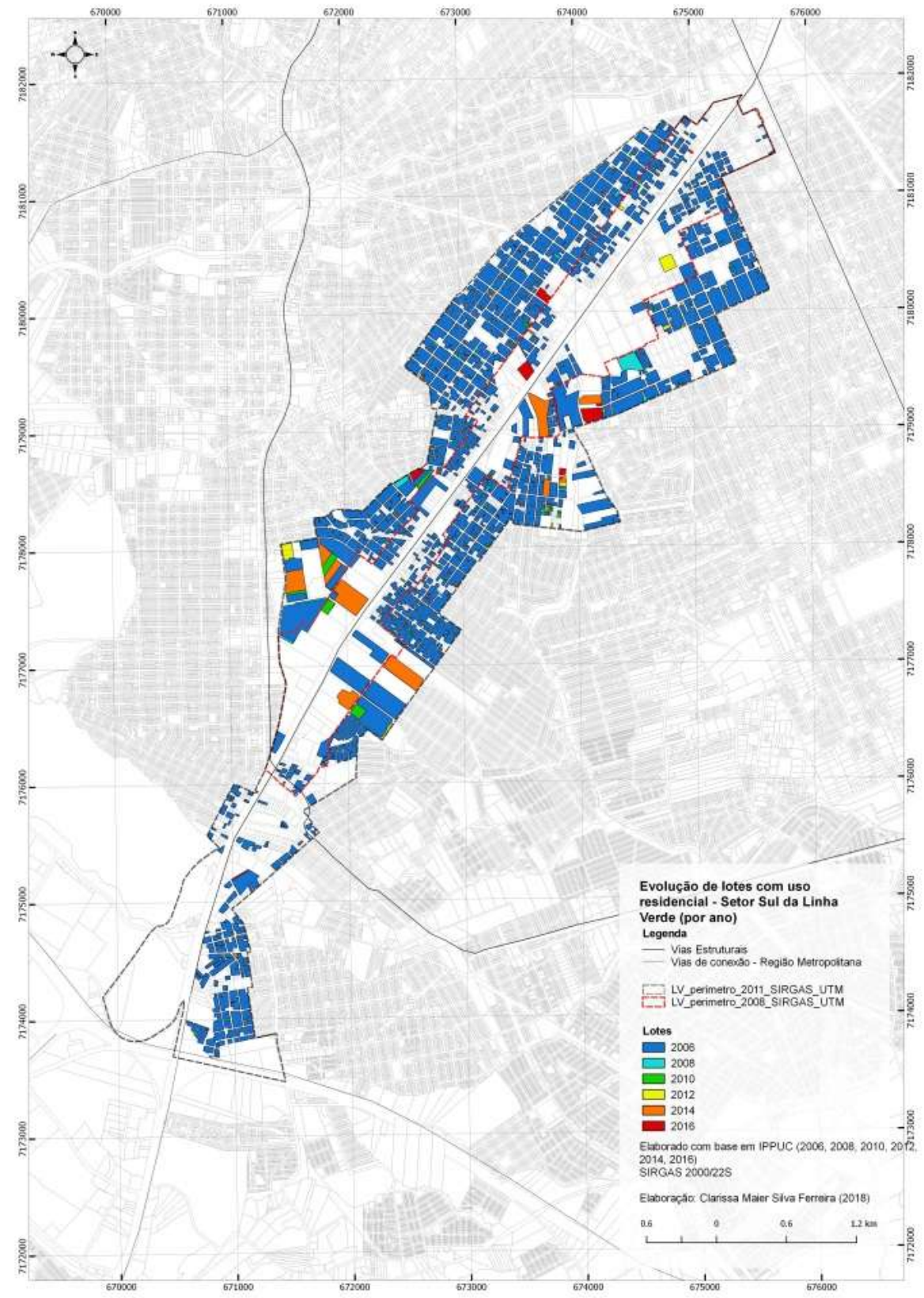

Evolução do número de lotes com uso residencial na OUC Linha Verde - setor sul

Fonte: Elaborado pela autora com base em IPPUC (2006, 2008, 2010, 2012, 2014, 2016)

O último indicador avaliado tratou da verificação da proporção de distribuição de superfície para uso terciário (comércio e serviços) em relação à superfície líquida da operação, como mecanismo para mensurar a diversidade da área. Os usos terciários concentram-se ao longo do eixo estrutural da Linha Verde, acomodando-se em uma estrutura fundiária de maiores dimensões, situação que já existia anteriormente ao período de análise e manteve-se nos últimos anos. Além disso, constata-se que o início da OUC não contribuiu para a variação na quantidade de lotes destinados ao uso terciário. 


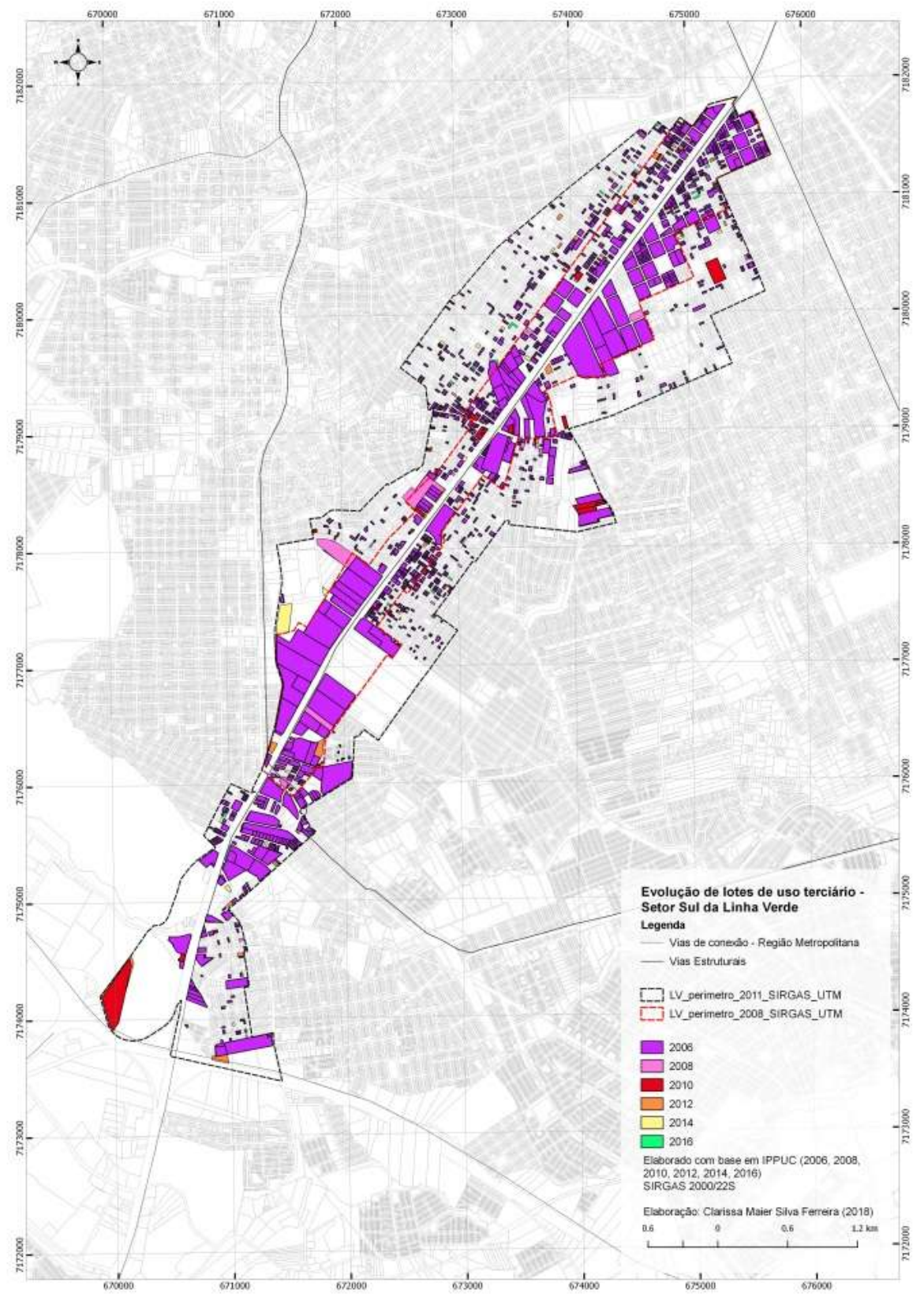

Evolução do número de lotes de uso terciário na OUC Linha Verde - setor sul

Fonte: Elaborado pela autora com base em IPPUC (2006, 2008, 2010, 2012, 2014, 2016)

Por outro lado, os usos residenciais, apresentam-se distribuídos no entorno não imediato ao eixo estrutural. No período temporal analisado, as áreas que incorporaram usos residenciais caracterizam-se, de modo geral, por terrenos onde foram implantados condomínios formados por conjunto de blocos, de oito ou mais pavimentos, indicando o início de uma tendência de maior adensamento local. 

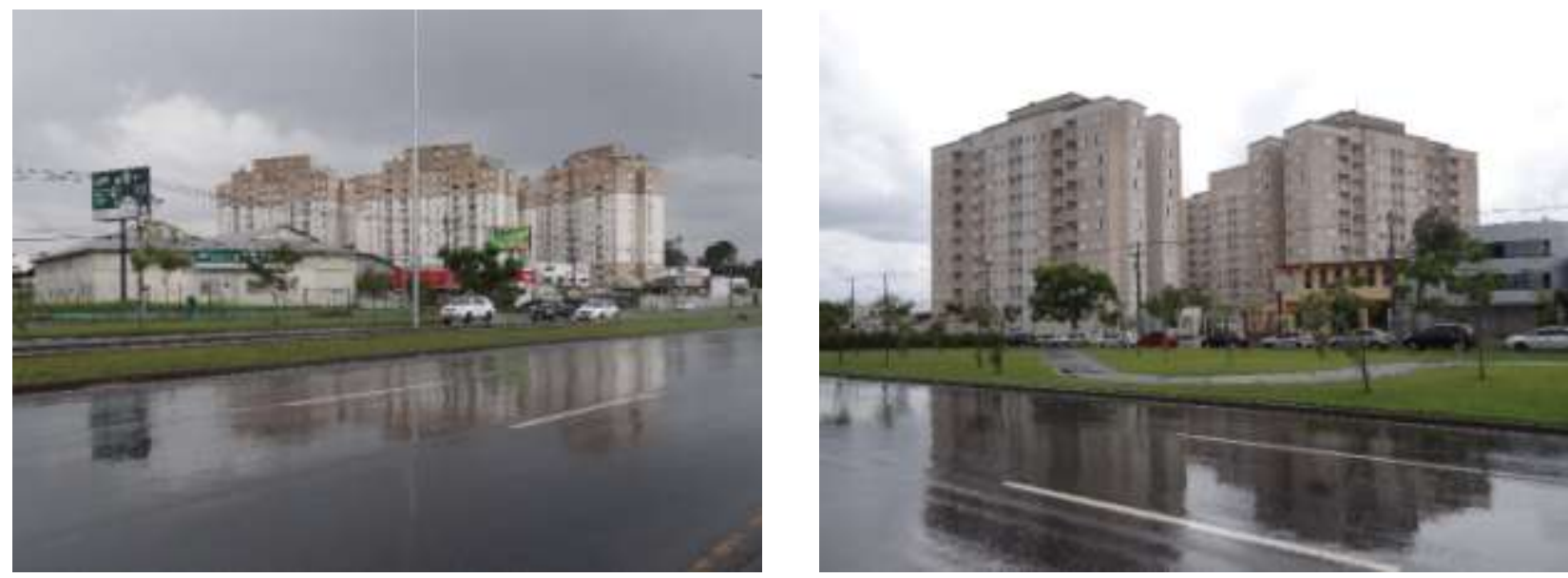

Empreendimentos imobiliários construídos na Linha Verde - setor sul, após a aprovação da OUC Linha Verde Fonte: Acervo da autora (2018)

Dessa forma, verifica-se que nos primeiros cinco anos de implementação da OUC as transformações morfológicas no território ainda se mostram incipientes em relação ao potencial da área, dada sua localização estratégica, na escala urbana e metropolitana. É relevante considerar que as preexistências locais, principalmente em relação à estrutura fundiária, bem como outros instrumentos urbanísticos, utilizados em locais da cidade reconhecidos como áreas mais vantajosas para investimentos pelo mercado imobiliário, podem ter influência significativa no processo de transformação da Linha Verde, retardando os resultados esperados.

Assim, verifica-se que embora a densidade da área esteja aumentando em função da presença de usos residenciais ao longo do período analisado, isso ainda não contribuiu com os resultados de diversidade de usos e aumento dos índices de compacidade, o que traria por consequência maior eficácia na gestão do solo urbano.

\section{CONSIDERAÇÕES FINAIS}

Essa pesquisa optou por um encaminhamento metodológico que propiciasse o entendimento geral do objeto de estudo, dada sua complexidade e extensão territorial. Portanto, reconhece-se as limitações do presente estudo no que diz respeito à necessidade de incorporação de outros critérios para aprofundamento das análises, a fim de verificar os resultados morfológicos decorrentes da implantação do GPU Linha Verde.

No entanto, os resultados obtidos até o presente momento permitem evidenciar um processo de transformação morfológica ainda incipiente, caracterizado, principalmente pela alteração de usos com a inserção de usos residenciais nesse território.

Ressalta-se que quando a OUC foi implementada, em 2011, as obras do setor sul, objeto de análise dessa pesquisa, já se encontravam totalmente concluídas. Ainda assim, a estrutura física apresentada não foi suficiente para atrair o interesse do mercado imobiliário como partícipe do processo de transformação desejável. Assim, há que se compreender por qual motivo a utilização do instrumento não propiciou uma transformação territorial mais significativa, de modo a permitir a total integração desse tecido à malha urbana.

No desenho da operação, o poder público também não considerou seu potencial como agente de desenvolvimento de algumas áreas estratégicas da operação, que funcionassem como promotoras de demandas, catalizando o processo de transformação. Ressalta-se que a maior parte das parcelas das áreas disponíveis no perímetro da OUC são de domínio privado, o que pode limitar o papel de atuação do Estado nesse sentido.

Assim, observam-se poucas alterações na estrutura morfológica desse território, apesar de toda a infraestrutura realizada. Há que se considerar que algumas externalidades podem ter contribuído com esse resultado, como, por exemplo, a crise política brasileira, todavia em vigor. 
A despeito disso, dada a localização estratégica dessa estrutura urbana, tanto em relação à escala urbana quanto metropolitana, reconhece-se seu potencial de contribuição com a reversão dos quadros de segregação socioespacial que caracterizaram o entorno desse espaço.

Dessa forma, outros critérios devem ser incorporados a presente pesquisa, como meio de aprofundar a análise desse objeto de estudo, além de aportar contribuições ao referencial teórico de GPUs no cenário brasileiro. No entanto, neste caso específico, ainda não se pode reconhecer como a utilização do instrumento contribuiu para o enfrentamento de questões emergentes nesse território.

\section{REFERÊNCIAS}

ACIOLY, C.; DAVIDSON, F. (1998). Densidade urbana: um instrumento de planejamento e gestão urbana. Rio de Janeiro: Mauad.

ALFONSIN, B. de M.(2006). Operações urbanas consorciadas como instrumento de captação de maisvalias urbanas: um imperativo da nova ordem jurídico-urbanística brasileira. In: FERNANDES, E.; ALFONSIN, B. de M. (Orgs.). Direito urbanístico: estudos brasileiros e internacionais.(287-300). Belo Horizonte: Del Rey.

BRASIL. Lei Federal № 10.257, de 10 de julho de 2001. Regulamenta os Artigos 182 e 183 da Constituição Federal, estabelece diretrizes gerais da política urbana e dá outras providências. Estatuto da Cidade. (2001) Diário Oficial [da] República Federativa do Brasil, Poder Executivo, Brasília, DF, 11 jul. 2001.

CURITIBA. Lei Municipal n. $\stackrel{0}{13.909}$, de 19 de dezembro de 2011. Aprova a operação urbana consorciada Linha Verde. (2011). Diário Oficial [de] Curitiba, Poder Executivo, Curitiba, PR, 19 dez. 2011.

DANTZIG, G. B.; SAATY, T. L. (1973). Compact City: Plan for a Liveable Urban Environment. São Francisco: W. H. Freeman.

DEMPSEY, N.; BROWN, C.; RAMAN, S.; PORTA, S.; JENKS, M.; JONES, C.; BRAMLEY, G. (2010). Elements os urban form. In: JENKS, M.;JONES, C. (Orgs.). Dimensions on the sustainable city. (21-51). Oxford: Springer.

FERRÁN, C. (2001). O efeito territorial dos grandes projetos urbanos. In ABRAMO, P. (Org.). Cidades em transformação: entre o plano e o mercado (p.239-260). Rio de Janeiro: Observatório Imobiliário e de Políticas do Solo.

FIX, M. (2001). Parceiros da exclusão: duas histórias da construção de uma "nova cidade" em São Paulo: Faria Lima e Água Espraiada. São Paulo: Boitempo.

GADENS, L; N.; HARDT, L. P. A.; FREY, K. (2011). Grandes projetos urbanos: evolução conceitual à luz da gestão urbana brasileira. XIV Encontro da Associação Nacional de Pós-Graduação e Pesquisa em Planejamento Urbano e Regional - ENANPUR XIV, Rio de Janeiro, maio (online).

HARVEY, D. (2000). Spaces of hope. Berkeley: University of California Press.

IBGE - Instituto Brasileiro de Geografia e Estatística. (2010). Censo demográfico. Brasília: IBGE.

IPPUC - Instituto de Pesquisa e Planejamento Urbano de Curitiba (2006). Base cadastral do Município. Curitiba: IPPUC.

IPPUC - Instituto de Pesquisa e Planejamento Urbano de Curitiba (2008). Base cadastral do Município. Curitiba: IPPUC.

IPPUC - Instituto de Pesquisa e Planejamento Urbano de Curitiba (2010). Base cadastral do Município. Curitiba: IPPUC. 
IPPUC - Instituto de Pesquisa e Planejamento Urbano de Curitiba (2012). Base cadastral do Município. Curitiba: IPPUC.

IPPUC - Instituto de Pesquisa e Planejamento Urbano de Curitiba; FIPE - Fundação Instituto de Pesquisas Econômicas (2012). Estudo de Impacto Ambiental da Operação Urbana Consorciada Linha Verde - EIA OUCLV. Curitiba: IPPUC.

IPPUC - Instituto de Pesquisa e Planejamento Urbano de Curitiba (2014). Base cadastral do Município. Curitiba: IPPUC.

IPPUC - Instituto de Pesquisa e Planejamento Urbano de Curitiba (2016). Base cadastral do Município. Curitiba: IPPUC.

JABAREEN, Y. R. (2006). Sustainable urban forms: their typologies, models and concepts. Journal of Planning Education and Research, n.26, p. 38-52.

JACOBS, J. (2000). Morte e vida das grandes cidades. São Paulo: Martins Fontes.

LAMAS, J. M. R. G. (2007). Morfologia urbana e desenho da cidade. Lisboa: Fundação Calouste Gulbenkian.

LU, C.; LIU, YI. (2015). Effects of China's urban form on urban air quality. Urban Studies, v. 53 (12), p. 26072623.

LUNGO, M. (2005). Grandes proyectos urbanos: una visión general. Urbana (Caracas), v. 37, p. 15-23. Disponível em:<http://190.169.94.12/ojs/index.php/rev_urb/article/view/5583/5367>. Acesso em: 20 jun. 2017.

MOULAERT, F.; RODRIGUEZ, A.; SWYNGEDOUW, E. (2003). The globalized city: economic restructuring and social polarization in european cities. Oxford: Oxford University Press.

OLIVEIRA, V. (Ed.) (2018). Diferentes abordagens em morfologia urbana. Contributos luso-brasileiros. Porto: UF Books. Disponível em: < http://www.vitoroliveira.fe.up.pt>. Acesso em 04 jan. 2018.

PORTAS, N. (2003). El surgimento del proyecto urbano. Perspectivas Urbanas (Barcelona), n. 3, 1-10.

ROSSI, A. (2001). A arquitetura da cidade. São Paulo: Martin Fontes.

RUEDA, S. (2012) El urbanismo ecológico. Barcelona: Agència d'Ecologia Urbana de Barcelona, s.d.

SILVA, E. L. da; MENEZES, E. M. (2005). Metodologia da pesquisa e elaboração de dissertação. Florianopólis: Editora da Universidade Federal de Santa Catarina - UFSC.

SOMECK, N.; CAMPOS NETO, C. M. (2005). Desenvolvimento local e projetos urbanos. Arquitextos 059, Texto Especial 059. Disponível em: <http://www.vitruvius.com.br/revistas/read/arquitextos/05.059/470>. Acesso em: 28 out. 2017.

ULTRAMARI, C.; REZENDE, D. A. (2007). Grandes projetos urbanos: conceitos e referenciais. Ambiente Construído (Porto Alegre), v. 7, p. 1-15. Disponível em: <http://www.seer.ufrgs.br/index.php/ambienteconstruido/article/viewArticle/3733>. Acesso em: 21 out. 2017.

VAINER, C.; OLIVEIRA, F. L.; LIMA JUNIOR, P. N. (2012). Notas metodológicas sobre a análise de grandes projetos urbanos. In: OLIVEIRA, F.L.de.; CARDOSO, A.L.; COSTA, H.S. de M.; VAINER, C.B. (Orgs.) Grandes projetos metropolitanos: Rio de Janeiro e Belo Horizonte (11-23). Rio de Janeiro: Letra Capital.

\section{AGRADECIMENTOS AS COLABORADORAS:}

A autora agradece a colaboração das estudantes voluntárias do Programa de Iniciação Científica que integram a pesquisa intitulada "Plano e projeto na cidade contemporânea: estudo a partir da relação entre uso e ocupação do solo e transporte coletivo à luz da experiência de Curitiba" (ID PROJETO: 23651, BANPESQ: 2016023651) desenvolvida no âmbito das atividades do Grupo de Pesquisa Cidade, Meio Ambiente e Políticas Públicas (CIMAPP) e do Laboratório de Habitação Urbanismo (LAHURB), do Departamento de Arquitetura e Urbanismo, Setor de Tecnologia, da Universidade Federal do Paraná (UFPR). 
Ciclo de pesquisa, período 2017-2018:

Clarissa Maier Silva Ferreira, Giovanna Pinhata de Andrade Gonzaga de Oliveira, Mayra Alves Zanin. 